\title{
Using microcomputers to control student-designed research in a research methods course
}

\author{
WALTER VOM SAAL \\ Millersville University, Millersville, Pennsylvania
}

\begin{abstract}
Microcomputers may be used to simulate traditional equipment in the psychology laboratory, such as tachistoscopes, memory drums, and reaction timers. With the diminishing price of microcomputers, such simulation is especially attractive, since it is considerably less expensive than the original special-purpose equipment, and also allows greater versatility. The undergraduate laboratory described here requires only inexpensive microcomputers, simple experimental control programs, and little or no additional peripheral equipment.
\end{abstract}

Microcomputers can be used in several ways in the undergraduate laboratory. One use is to allow students to duplicate relatively sophisticated research studies that have previously been published. Another use is to allow on-line control of experiments, in which the computer is connected to external stimulus-presentation and response-recording devices and special programs are written to specify the relations among these. A third approach is illustrated in the present paper: Microcomputers may be used to simulate traditional apparatus of the experimental psychology laboratory, such as tachistoscopes, memory drums, and reaction timers. Such simulation is possible with relatively simple programs and in most cases with no external devices beyond the keyboard and monitor. With the diminishing price of microcomputers, such simulation is especially attractive, since it is considerably less expensive than the original special-purpose equipment and also much more versatile.

We use microcomputers in this way in two laboratory courses in statistics and research design, which are required basic courses for our 250 undergraduate majors. In these courses, students work individually or in pairs to design and carry out simple research studies whose data they then can analyze statistically. Since we have only a limited amount of traditional laboratory equipment, most of this research has previously been carried out in the field. However, over the past year, we have established a laboratory with six independent microcomputer-based experimental stations. Programs have been developed to allow control of simple experiments that students can modify to test their own hypotheses. As one illustration, a simple reaction time program allows the experimenter to specify parameters such as characteristics of the stimulus, time between trials, and so on. The student can then design a study to test the effect of

Atari computer users are invited to correspond with the author at: Department of Psychology, Millersville University, Millersville, PA 17551. We will be happy to share programs. one or more of these parameters. The student can also use the program to test the effect of some other variable on reaction time, such as sleep deprivation.

This paper describes some of the hardware and software used in our microcomputer laboratory. Its purpose is to suggest the kinds of things that can be done with inexpensive microcomputers and little additional hardware.

\section{PHYSICAL SETTING}

The microcomputers are located in a single room. The equipment constituting each station is set on a small movable desk. (A work desk is a very worthwhile investment.) We found it necessary to add a tray mounted on the rear of each station to hold the power outlet strip, several power transformers, and many wires and connectors associated with each station. We also found it important to have room for at least two chairs (for experimenter and subject) at each station and a small table between adjacent stations to provide additional writing surface.

\section{HARDWARE}

Atari microcomputers were chosen because of their excellent graphics capabilities and low cost. Although less software was available for the Atari than for other computers, such as the Radio Shack TRS- 80 and the Apple II, the programs we needed were not available on other computers and we planned to develop our own programs. In addition to my previous programming experience on the Atari, programming support was available from staff and students of the university's Computer Science Department. Much of our programming is carried out as course projects by computer science students.

The laboratory contains several experimental stations at different levels of sophistication. Table 1 indicates 
Table 1

Sample Work Station Configurations

\begin{tabular}{|c|c|c|}
\hline $\begin{array}{c}\text { Minimal } \\
\text { Configuration }\end{array}$ & $\begin{array}{c}\text { Standard } \\
\text { Configuration }\end{array}$ & $\begin{array}{l}\text { Program Development } \\
\text { and Word Processing }\end{array}$ \\
\hline $\begin{array}{l}\text { Atari } 400,16 \mathrm{~K} \\
\mathrm{~B} / \mathrm{W} \text { television } \\
\text { tape recorder }\end{array}$ & $\begin{array}{l}\text { Atari } 800,48 \mathrm{~K} \\
\text { color monitor } \\
\text { tape recorder } \\
\text { work table }\end{array}$ & $\begin{array}{l}\text { Atari } 800,48 \mathrm{~K} \\
\text { color monitor } \\
\text { disk drive } \\
\text { work table }\end{array}$ \\
\hline \multirow[t]{3}{*}{ Approximate Cost: $\$ 350.00$} & 40 -column printer & $\begin{array}{l}80 \text {-column printer } \\
\text { printer interface }\end{array}$ \\
\hline & $\begin{array}{l}\text { Approximate Cost: } \$ 1200.00 \\
\text { (with disk drive } \\
\text { instead of tape } \\
\text { recorder: } \$ 1535.00 \text { ) }\end{array}$ & $\begin{array}{l}\text { high-resolution } \\
\text { green monitor } \\
80 \text {-column board } \\
32 \mathrm{~K} \text { board } \\
\text { commercial word } \\
\text { processing program }\end{array}$ \\
\hline & & Approximate Cost: $\$ 2600.00$ \\
\hline
\end{tabular}

three configurations, with prices at the time of purchase. Prices for equivalent systems are now considerably lower.

In addition to the basic hardware indicated in Table 1, the following equipment is available:

(1) Input devices. These include joysticks, paddle controllers, external pushbuttons wired to game input ports, and relay closures from external devices wired to game input ports.

(2) Speech synthesizers. Two different types are in the laboratory, but both are of limited use. The speech is difficult to understand unless the user reads printed words on the screen while listening to them, or a very restricted number of alternatives is presented. Some students are expected to use these devices for auditory discrimination experiments.

(3) Output devices. Game ports have been wired to control LED indicator lights and relays. The relays, in turn, can control external devices, such as slide projectors.

(4) Voice key. The voice key circuit in Radio Shack's inexpensive "Science Fair 150 in One Electronic Project Kit" is adequate. Its relay closure output is wired to the game controller input port and detected as if it were a joystick button.

(5) A special two-channel tape recorder. This recorder is used in certain auditory detection experiments, and is described in more detail in the next section below.

Although this equipment is available, it is not neces. sary for most of our programs. We have avoided more sophisticated equipment that involves biofeedback, analog-to-digital conversion devices, recording of blood pressure, puise rate, and GSR, etc.

\section{SAMPLE PROGRAMS}

Several programs have been written, and others are under development. Computer science students write at least one additional general-purpose program for us each semester, so that a library of usable programs is being developed.
The following programs indicate the kind of experimental control programs we use. These can be written fairly simply, usually in BASIC. In most cases, they require no additional peripheral equipment beyond the computer, keyboard, monitor, and perhaps an input device such as a button or joystick. Data are printed out for the experimenter on an inexpensive printer, but can be displayed on the screen and copied by the student experimenter if a printer is not available.

(1) Tachistoscope simulation. This simulation allows specification of Display \#1, Display \#2, and presentation times for each display. Times can increase or decrease each trial by a specified amount. The program allows simple experiments on thresholds. Experiments on backward masking can be done by varying the background display.

(2) Memory drum simulation. This simulation simply presents a list of words at a specified presentation rate. The same types of experiments can be done that are done with a traditional memory drum.

(3) Simple reaction time. A stimulus appears on the screen after a variable delay period, and subject reaction time is recorded. Trial-by-trial and summary data are printed after each specified set of trials. The experimenter may vary the nature of the stimulus, its size and location on the screen, whether it appears in fixed or variable positions, number of trials, intertrial intervals, and other parameters.

(4) Choice reaction time. This is similar to the above, with two stimuli and two responses. Times for correct responses and errors are recorded separately.

(5) Reaction time with variable numbers of alternatives. Letters or symbols are presented from a list entered by the experimenter, and the subject must match them on the keyboard. Students can form hy. potheses about the effects of numbers of alternatives, and can also manipulate probabilities of occurrence of each alternative.

(6) Auditory detection studies. A special two-channel tape recorder is used. The recorder allows markers in one channel to close a relay that normally is used 
to advance a slide projector. This relay is wired to a game input port so the computer can detect it as if it were a joystick button. The student then creates an audio tape with target words, and markers are added to the second channel of the tape beside each target word. The computer program starts a timer whenever the marker appears and stops the timer when the subject presses a button. This allows for measurement of the time needed to detect the target words. Students can design experiments in which they manipulate the nature of the target words, frequency of target words, verbal material preceding the target words, and so on.

(7) Personality test presentation. It is fairly easy to present an objective personality test to subjects using the computer. Although this facilitates test scoring and preliminary data analysis, these advantages alone may not justify the programming effort and computer time involved, especially since only one subject can be run at a time. However, computerized testing is valuable when a test score (e.g., low or high anxious) is used to determine the experimental group to which a subject is assigned and the subsequent stimuli to be presented to the subject. The computer does this automatically, with no delay.

\section{TYPICAL PROGRAM USE}

Students are taught to use the computers as part of the research methods courses. In the computer room, instructions that explain how to turn on the computers and peripherals and how to load tapes and disks are posted. Also posted are the following instructions, which apply to most programs:

(1) To interrupt any program, press BREAK.

(2) To resume the program where interrupted, type "CONT" and press RETURN. (Existing data will be retained, but some timing of events may be disturbed, since program clocks may keep running during the break.)

(3) To cancel any program and start all over, press SYSTEM RESET, then type "RUN" and press RETURN. This will cause existing data to be erased.

(4) To go to main menu of program without losing existing data, press BREAK or SYSTEM RESET, then type "GOTO RESTART" and press RETURN.
These instructions assume the experimental control program in use is written in Atari BASIC and has defined within it an appropriate address labeled "RESTART." (This is possible in Atari BASIC but may not be possible in other versions of BASIC.) Normally, this restart address returns the user to the main menu.

A sample program run includes the following stages:

(1) The program automatically loads from disk or tape.

(2) The program name, identifying the number and date of the most recent revision, and a brief description appear on the screen.

(3) The question "Do you want instructions ( $Y$ or N)?" appears at the bottom of the screen.

(4) If the user answers "Y," then a description of the program and detailed instructions appear on the screen, displayed one page at a time. The bottom line of each screen displays the instruction "press RETURN to continue ...." Further instructions are also available at other points in the program.

(5) A menu appears asking the user to select among various program options. Typical options include:

a. Show instructions.

b. Show existing parameter values.

c. Change to new parameter values.

d. Run Experiment \#1 (e.g., simple reaction time experiment).

e. Run Experiment \#2 (e.g., choice reaction time experiment).

f. Show data on screen.

g. Store data on disk or tape.

h. Print data on printer.

i. Terminate program.

\section{CONCLUSIONS}

The kind of laboratory described here has several advantages: Experimental stations can be established at relatively low cost; control programs are fairly easy to write; and individual students can use the programs to conduct a variety of simple research studies of their own design. Pedagogically, the present approach may offer advantages over more complex and sophisticated packaged programs, in which the student may have less input into the experimental design and the selection of independent variables to manipulate. 